BMJ Open

Diabetes

Research

\& Care

\section{Mixed methods study of engagement in behaviors to prevent type 2 diabetes among employees with pre-diabetes}

To cite: Kullgren JT, Knaus M, Jenkins KR, et al. Mixed methods study of engagement in behaviors to prevent type 2 diabetes among employees with prediabetes. BMJ Open Diabetes Research and Care 2016;4: e000212. doi:10.1136/ bmjdrc-2016-000212

- Additional material is available. To view please visit the journal (http://dx.doi.org/ 10.1136/bmjdrc-2016000212).

Received 11 February 2016 Revised 30 July 2016 Accepted 23 August 2016

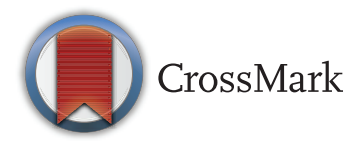

For numbered affiliations see end of article.

Correspondence to Dr Jeffrey T Kullgren; jkullgre@med.umich.edu

\section{ABSTRACT}

Background: Many employers use screenings to identify and recommend modification of employees' risk factors for type 2 diabetes, yet little is known about how often employees then engage in recommended behaviors and what factors influence engagement. We examined the frequency of, facilitators of, and barriers to engagement in recommended behaviors among employees found to have prediabetes during a workplace screening.

Methods: We surveyed 82 University of Michigan employees who were found to have pre-diabetes during a 2014 workplace screening and compared the characteristics of employees who 3 months later were and were not engaged in recommended behaviors. We interviewed 40 of these employees to identify the facilitators of and barriers to engagement in recommended behaviors.

Results: 3 months after screening, $54 \%$ of employees with pre-diabetes reported attempting to lose weight and getting recommended levels of physical activity, had asked their primary care provider about metformin for diabetes prevention, or had attended a Diabetes Prevention Program. These employees had higher median levels of motivation to prevent type 2 diabetes $(9 / 10$ vs $7 / 10, p<0.001)$ and lower median estimations of their risk for type 2 diabetes ( $40 \%$ vs $60 \%, p=0.02)$. Key facilitators of engagement were high motivation and social and external supports. Key barriers were lack of motivation and resources, and competing demands.

Conclusions: Most employees found to have prediabetes through a workplace screening were engaged in a recommended preventive behavior 3 months after the screening. This engagement could be enhanced by optimizing motivation and risk perception as well as leveraging social networks and external supports.

\section{INTRODUCTION}

Nearly $30 \%$ of US adults have pre-diabetes, ${ }^{1}$ an asymptomatic condition associated with a threefold greater annual incidence of type 2 diabetes $^{2}$ and a $50 \%$ greater risk of developing cardiovascular disease. ${ }^{3-6}$ The landmark Diabetes Prevention Program (DPP) trial demonstrated that patients with pre-diabetes can significantly reduce their risk of

\section{Key messages}

- Most employees found to have pre-diabetes through a workplace screening were engaged in a recommended strategy to prevent type 2 diabetes about 3 months after the screening.

- Self-directed efforts to lose weight and achieve recommended levels of physical activity were more common than participation in a Diabetes Prevention Program or use of pharmacotherapy.

- Key facilitators of engagement in behaviors to prevent type 2 diabetes were high motivation, assistance and encouragement from social networks, and use of external supports such as tracking devices.

- Important barriers to engagement in behaviors to prevent type 2 diabetes were low motivation, competing demands, and insufficient resources to support healthy behaviors.

developing type 2 diabetes through weight loss and physical activity or use of metformin. ${ }^{78}$ Owing to the effectiveness ${ }^{7}$ and costeffectiveness ${ }^{8}$ of these strategies, the Centers for Disease Control and Prevention (CDC) is now disseminating the DPP in communities across the USA, ${ }^{9}$ and many insurers are now covering the DPP. ${ }^{10}$

Identification of individuals who could benefit from these preventive strategies begins with screening tests ${ }^{11}$ that are widely available in healthcare settings and are increasingly being conducted as part of workplace screenings which feature health risk appraisals (HRAs), blood draws or both. ${ }^{12} 13$ Such screenings represent an opportunity to help at-risk individuals better understand their risk for type 2 diabetes and engage in behaviors that could help them to reduce this risk. These screenings are likely to accelerate in use due to the Prevent Diabetes STAT initiative, a joint effort by the American Medical Association (AMA) and CDC to identify more Americans with pre-diabetes and connect them with DPPs, ${ }^{14}$ and the US Preventive Services Task Force's recent broadening of criteria for screening for type 2 diabetes. ${ }^{15}$ 
Currently there are evidence-based strategies to help at-risk individuals prevent or delay their progression to type 2 diabetes, widely available ways to identify individuals who might benefit, and national initiatives to identify more patients with pre-diabetes. However, little is known about how people actually respond to being told they have pre-diabetes following a screening test. ${ }^{16-20}$ This lack of evidence limits understanding of the effects of current practices and precludes the development of effective strategies to optimize engagement of at-risk individuals in preventive strategies. Accordingly, the objective of this mixed methods study was to describe the frequency of, facilitators of, and barriers to engagement in recommended behaviors to prevent type 2 diabetes among employees found to have pre-diabetes during a workplace screening.

\section{METHODS}

\section{Study sample}

We conducted a mixed methods observational study of University of Michigan (U-M) employees who were found to have pre-diabetes during employer-sponsored screenings organized by MHealthy, U-M's campus-wide wellness program. The screenings were advertised through email and flyers and conducted across multiple days and times at numerous locations. Employees of U-M were offered a $\$ 100$ incentive for completing the screening, which included an HRA and measurements of body mass index (BMI), blood pressure, blood glucose, and cholesterol. Participants were asked, but not required, to be fasting. Screenings were conducted between 1 January 2014 and 31 May 2014.

Screening test results were communicated in person by a registered nurse health coach from The StayWell Company, LLC ('StayWell'). Prior to the communication of fasting blood glucose (FBG) test results, the health coach verified that the employee had been fasting. When an employee had an FBG measurement of 100 to $125 \mathrm{mg} / \mathrm{dL}$ (inclusive), the health coach informed the employee that their FBG was in the pre-diabetes range and provided brief counseling about this condition using talking points based on American Diabetes Association ${ }^{21}$ and National Diabetes Prevention Program ${ }^{9}$ guidelines (see online supplementary figure S1). Employees with pre-diabetes were also provided with a one-page handout that summarized these points and listed contact information for local DPPs.

\section{Recruitment}

Employees identified as having pre-diabetes during screenings were invited by the StayWell health coaches to be contacted by our research team to learn more about a study 'designed to identify ways to help people prevent type 2 diabetes'. Employees who agreed to be contacted signed a form and provided their contact information. Research staff then contacted these individuals by phone or email. Those who were willing to participate were emailed a survey link to an online informed consent document.

\section{Online surveys}

Individuals who provided their free and informed consent were asked to complete two online surveys. A link to the first survey was emailed to participants as soon as possible after they provided informed consent. This first survey inquired about demographics and health literacy, ${ }^{22} 23$ and served as an initial contact with participants to facilitate subsequent data collection in the second survey. The first survey was completed in a median of 18.5 days after screenings (IQR 9-34). The response rate for the first survey was $100 \%$.

Approximately 2 months after completion of the first survey, participants were emailed a link to a second survey. This survey contained questions about engagement in our key behaviors of interest such as, stage of change related to weight loss, discussing pharmacotherapy, and participating in a DPP; ${ }^{24}$ and physical activity in the past 7 days. ${ }^{25}$ This survey also included questions about potential mediators of engagement in our key behaviors of interest, such as knowledge of whether type 2 diabetes is preventable; perceptions of risk for type 2 diabetes; ${ }^{26}{ }^{27}$ level and locus of motivation to prevent type 2 diabetes; ${ }^{28}$ and perceived competence to (1) attempt weight loss, (2) increase physical activity, (3) discuss with one's primary care provider pharmacotherapy for prevention of type 2 diabetes, and (4) participate in a DPP. ${ }^{29}$ We measured locus of motivation to prevent type 2 diabetes using the Treatment Self-Regulation Questionnaire (TSRQ). The TSRQ includes subscales that permit measurement of three different types of motivation: autonomous motivation (ie, motivation that comes from internal sources), controlled motivation (ie, motivation that comes from external sources), and amotivation (ie, the absence of motivation) ${ }^{28}$ These three motivational constructs are important because autonomous motivation is more likely to produce long-term, sustained healthy behaviors relative to either controlled motivation or amotivation. ${ }^{30}$ The second survey was completed in a median of 94 days after screenings (IQR 78111). The response rate for the second survey was $96 \%$.

For both surveys, participants received email reminders to encourage completion. After 10 attempts to contact, participants were categorized as being lost to follow-up. Participants received a $\$ 10$ gift card for each survey completed. All surveys were completed between February and October 2014.

\section{Semistructured telephone interviews}

After the surveys, we conducted semistructured telephone interviews with participants to identify facilitators of and barriers to engagement in behaviors to prevent type 2 diabetes. For purposive sampling, we categorized participants based on a manual review of their second survey responses as either (1) attempting weight loss and having gotten at least 150 min of moderate physical 
activity in the past week, having discussed pharmacotherapy for prevention of type 2 diabetes with a primary care provider since the screening, or participating in a DPP; or (2) not having carried out any of these things recommended to them at the screening. We then randomly selected participants in each of these 2 groups and asked them via email to participate in a telephone interview. Interviews consisted of open-ended questions which aimed to elicit participant-identified facilitators of and barriers to engagement in recommended behaviors (ie, factors that participants felt made behavior change easier and harder, respectively), as well as emotional reactions to receiving a pre-diabetes diagnosis, understanding of pre-diabetes, and reasons for any behavior changes.

Participants who were invited to participate in an interview received email reminders to set up an interview appointment, and after 10 unsuccessful attempts to contact were categorized as being lost to follow-up. Participants who completed an interview received a $\$ 10$ gift card. In each of the two groups, we stopped conducting interviews once we reached thematic saturation. Eighty-three per cent of participants who were invited to be interviewed completed an interview. All interviews were conducted between August and November 2014.

\section{Statistical analysis}

We used data from both surveys to compare demographic characteristics and potential behavioral mediators of participants who either (1) were attempting weight loss and had gotten at least 150 min of moderate physical activity in the past week, had discussed pharmacotherapy for prevention of type 2 diabetes with a primary care provider since the screening, or were participating in a community DPP; or (2) had not carried out any of these things recommended to them at the screening. We compared continuous variables using Wilcoxon rank-sum tests. For categorical variables we used $\chi^{2}$ tests or Fisher's exact tests. We used Stata V.13 (Stata Corp, College Station, Texas, USA) to conduct all analyses.

\section{Qualitative analysis}

All interviews were audio recorded and transcribed verbatim. Four members of the research team independently reviewed a subset of transcripts using modified grounded theory to identify salient themes. ${ }^{31}$ They then met to discuss the themes, refine them, and achieve consensus on codes and their definitions. Once the coding scheme was established, two members of the research team independently coded all transcripts in Dedoose software. They then met to discuss their coding and resolve differences by consensus. After all transcripts were double-coded, the research team met to discuss the code summaries and memos, and to identify key themes with a focus on facilitators of and barriers to engagement in recommended behaviors. ${ }^{32}$
The study protocol was approved by the University of Michigan Medical School Institutional Review Board. Data were analyzed in 2015.

\section{RESULTS}

\section{Sample characteristics}

Of the 17310 U-M employees who attended the screenings, 5279 provided an FBG and 523 had an FBG in the pre-diabetes range. Eighty-five of these 523 pre-diabetic individuals consented to study participation and 82 completed both surveys (see online supplementary figure S2). Most (72.0\%) of the participants were women, white $(73.2 \%)$, and had at least a college education $(59.8 \%$ ). The median age was 50.5 (IQR 40 to 56.5) and the median household income was $\$ 75000$ (IQR $\$ 55000$ to $\$ 125000)$. Approximately two-thirds (65.9\%) had never been told they have pre-diabetes (see online supplementary table S1). The age, gender, and race of the 82 employees who consented to and completed both surveys were not significantly different from the 523 employees who in the screening had an FBG of 100 to $125 \mathrm{mg} / \mathrm{dL}$.

\section{Quantitative analyses}

Approximately 3 months after the screening, $53.7 \%$ of participants were engaged in at least one strategy to prevent type 2 diabetes that had been recommended to them by a health coach at the screening (figure 1). Most participants $(79.3 \%)$ were trying to lose weight, and most $(57.3 \%)$ reported they had gotten at least $150 \mathrm{~min}$ of at least moderate physical activity in the last week. Fewer than half $(45.1 \%)$ reported they were trying to both lose weight and had gotten at least $150 \mathrm{~min}$ of at least moderate physical activity in the last week. Nearly 1 in $5(18.3 \%)$ had talked with a primary care provider about whether metformin for prevention of type 2 diabetes would be right for them. Few (3.7\%) reported having participated in a DPP in the past 30 days.

Compared with participants who were not engaged in at least one recommended strategy to prevent type 2 diabetes (ie, 'non-engagers'), there were no differences in the demographic characteristics of participants who were engaged in at least one recommended strategy (ie, 'engagers') (table 1). Compared with non-engagers, engagers reported higher median levels of motivation to prevent type 2 diabetes (9 vs 7 (on a scale of 1-10), $\mathrm{p}=<0.001$ ), higher median levels of personal importance of avoiding type 2 diabetes ( 10 vs 9 (on a scale of 1-10), $\mathrm{p}=0.01$ ), and lower median estimations of their risk for developing type 2 diabetes in the next 3 years $(40 \%$ vs $60 \%, \mathrm{p}=0.02)$. Engagers also had higher median levels of autonomous motivation (6.3 vs 5.8 (on a scale of $1-7), \mathrm{p}=0.02$ ) and controlled motivation (4.4 vs 3.7 (on a scale of $1-7$ ), $\mathrm{p}=0.02$ ) to prevent type 2 diabetes, as well as higher median patient activation scores (70.2 vs 63.1 (on a scale of $0-100$ ), $\mathrm{p}=0.002$ ). There were no other statistically significant differences between the 
Figure 1 Engagement in recommended behaviors to prevent type 2 Diabetes $(n=82)$. *Defined as (1) attempting weight loss and reporting at least 150 min of at least moderate level physical activity in the past 7 days, (2) having talked with one's healthcare provider about metformin for T2DM prevention since the screening, or (3) having attended a community Diabetes Prevention Program in the past 30 days. DPP, Diabetes Prevention Program; PCP, primary care provider; T2DM, type 2 diabetes mellitus.

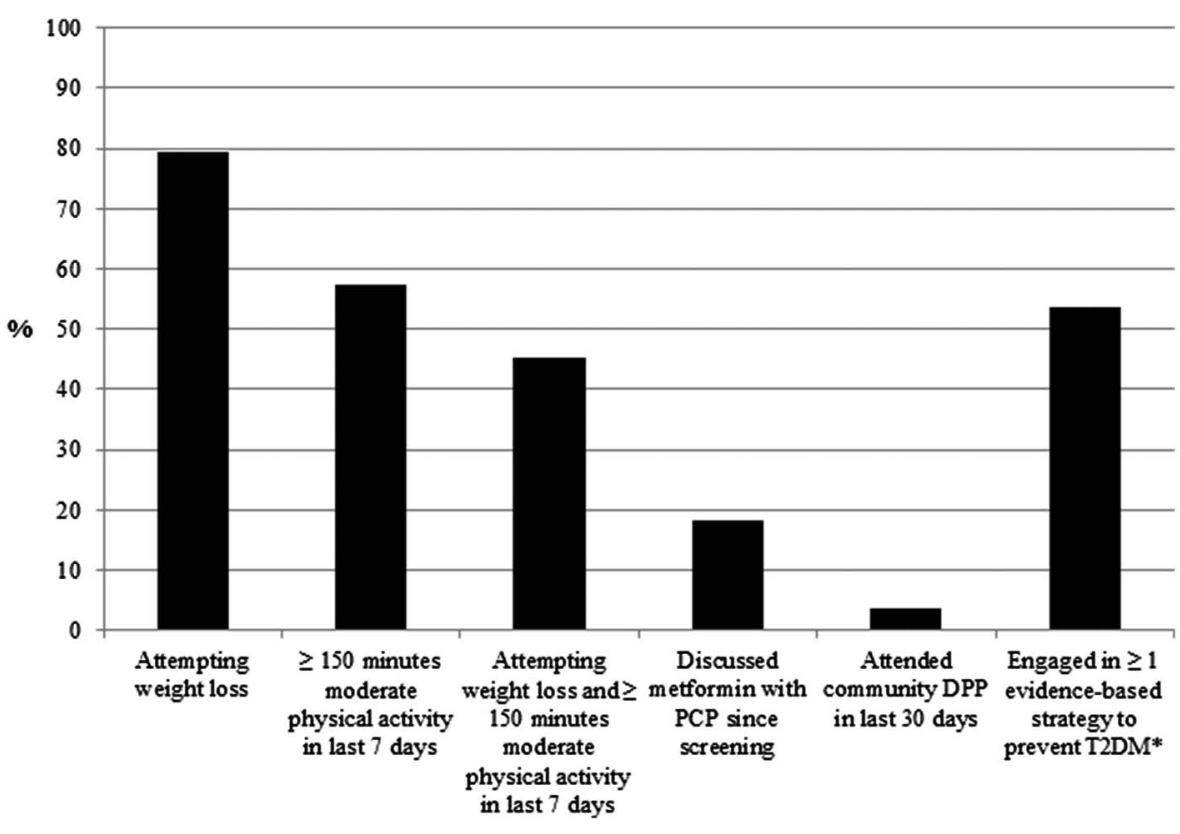

Table 1 Employee characteristics by engagement in recommended preventive behaviors $(n=82)$

\begin{tabular}{|c|c|c|c|}
\hline Characteristic (N (\%) or median (IQR)) & Engaged $^{\star}(n=44)$ & Not engaged $(n=38)$ & p Valuet \\
\hline \multicolumn{4}{|l|}{ Demographics } \\
\hline Median age & $51(41-57)$ & $50(36-55)$ & 0.62 \\
\hline Female & $33(75.0)$ & $26(68.4)$ & 0.51 \\
\hline Minority race $\ddagger$ & 7 (15.9) & $13(34.2)$ & 0.05 \\
\hline Hispanic ethnicity & $0(0.0)$ & $2(5.3)$ & 0.21 \\
\hline College education & $23(52.3)$ & $26(68.4)$ & 0.14 \\
\hline Median income§ & $\$ 80000$ (55 000-125 000) & $\$ 65000$ (45 000-95 000) & 0.32 \\
\hline Previous pre-diabetes diagnosis & $18(40.9)$ & $10(27.0)$ & 0.19 \\
\hline \multicolumn{4}{|l|}{ Potential behavioral mediators } \\
\hline Knowledge that T2DM is preventable & $38(86.4)$ & $28(75.7)$ & 0.26 \\
\hline Estimated risk of getting T2DM & $40 \%(20-60)$ & $60 \%(40-80)$ & 0.02 \\
\hline Level of importance of avoiding T2DMף & $10(9-10)$ & $9(7-10)$ & 0.01 \\
\hline Level of motivation to avoid T2DMף & $9(7.5-10)$ & $7(5-8)$ & $<0.001$ \\
\hline \multicolumn{4}{|l|}{ Locus of motivation to prevent T2DM" } \\
\hline Autonomous ${ }^{\star \star}$ & $6.3(5.5-6.9)$ & $5.8(4.8-6.6)$ & 0.02 \\
\hline Controlled ${ }^{* *}$ & $4.4(3.5-5.5)$ & $3.7(2.5-4.2)$ & 0.02 \\
\hline Amotivation ${ }^{\star \star}$ & $2.0(1.3-3.0)$ & $2.0(1.3-3.0)$ & 0.74 \\
\hline Relative autonomous motivation index $† \dagger$ & $1.8(0.8-2.7)$ & $2.0(0.7-2.9)$ & 0.80 \\
\hline \multicolumn{4}{|l|}{ Perceived competence $\ddagger \ddagger$} \\
\hline Lose weight & $4.5(4.0-5.8)$ & $4.5(3.3-5.7)$ & 0.44 \\
\hline Increase physical activity & $5.0(4.0-6.0)$ & $4.3(3.0-6.0)$ & 0.07 \\
\hline Ask about pharmacotherapy & $6.0(5.0-7.0)$ & $6.0(4.3-7.0)$ & 0.55 \\
\hline Participate in wellness programs & $5.7(4.0-6.3)$ & $5.0(3.3-6.0)$ & 0.26 \\
\hline Patient activation score $\S$ & $70.2(65.5-77.7)$ & $63.1(55.6-67.8)$ & 0.002 \\
\hline
\end{tabular}

${ }^{*}$ Engagement defined as (1) currently trying to lose weight and reporting at least 150 min of at least moderate level physical activity in the past 7 days, (2) having talked with one's healthcare provider about pharmacotherapy for T2DM prevention since the screening, or (3) having attended a Diabetes Prevention Program in the past 30 days.

†From Wilcoxon Rank Sum tests for continuous variables and $\chi^{2}$ tests or Fisher's exact tests for categorical variables. $\neq$ Defined as any race other than White.

§Income data collected in categories. For analyses, each participant's income was coded as the midpoint of the annual household income range they indicated.

ףMeasured on a scale of 1-10. Higher scores indicate greater levels.

${ }^{\star *}$ Measured on a scale of 1-7 using the Treatment Self-Regulation Questionnaire (TSRQ). Higher scores indicate greater levels of each dimension.

††Autonomous motivation score minus controlled motivation score. Both measured using the TSRQ.

$\ddagger \ddagger$ Perceived competence to engage in each behavior measured on a scale of $1-7$ using the Perceived Competence Scale. Higher scores indicate greater levels of perceived competence to engage in that behavior.

$\S \S$ Measured on a scale of $0-100$ using the Patient Activation Measure. Higher scores indicate greater levels of activation.

T2DM, type 2 diabetes mellitus. 
engagers and non-engagers in potential mediators of engagement in behaviors to prevent type 2 diabetes such as a previous diagnosis of pre-diabetes, knowledge that type 2 diabetes is preventable, or perceived competence to engage in each recommended preventive behavior.

\section{Qualitative analyses}

We conducted semistructured telephone interviews with 22 engagers and 18 non-engagers. From these interviews, key themes emerged about participant-identified facilitators of engagement in behaviors to prevent type 2 diabetes (box 1) and barriers to engagement (box 2).

Among the 22 engagers, the two predominant facilitators of engagement in behaviors to prevent type 2 diabetes, each cited by 14 participants, were the support from a member of their social network (eg, family or friends) and use of external resources or tools, such as rewards and activity trackers. For example, one participant who cited the support of social network members said, "It was helpful to me that I have family members who have experienced the same thing... having both family members that I could talk to that have gone through this..." A participant who used an activity tracker said, "I have a Fitbit that makes it easier cause I like to challenge myself to make sure I get my steps in every day. So, lots of times, I'll get home in the evening and I'll see them at 9000 steps and I'll like, go out and walk up and down the driveway." Motivation to avoid

Box 1 Main facilitators and illustrative quotes from interviews with employees engaged in recommended behaviors

\section{Support from social network}

"Having the family involved in and supportive... of those changes helps because if....we all don't change diet or...make time to be more active then it's hard for me to do it on my own."

- "I have made the choice that 3 days a week l'm going to... attend a class and work out...As a family we've chosen to be active...not only just for me but for the whole family."

Use of external supports

- "That is a huge motivator for me, to have to go log into the computer...I really thought about it a lot more...I have to think that it's the...emails you know that we get reminding us to record our time and all of the other little links to personal stories and recipes and those things seem to plant a seed in my head."

- "I have some reminders on my phone...I have a weight checking app that I got just recently...I do not expect them to maintain my attention for very long but while I am using them they keep it more frame of mind."

High motivation

- "I just kind of want to get myself back in shape and...healthy you know because I am getting older so I want to get... healthier now."

- "I have access to working out and everything, and I just think I'm more motivated because I don't want it (pre-diabetes) to progress."
Box 2 Main barriers and illustrative quotes from interviews with employees not engaged in recommended behaviors

\section{Competing demands}

- "I definitely didn't participate in anything... mainly because of time, and I knew I was stretched pretty thin as it was, and it would just feel like one more obligation that I couldn't follow through on."

- "There is always more work than time and so when I walk away from my desk to get on the treadmill, I am letting something sit that could be done and that is the way we all feel I think."

Low motivation

- "Mentally I know what I need to do...I don’t know if I want to call it the leap, but I need to make the commitment and then hold myself accountable for it, and that is where I struggle."

- "I know that (exercise) would work for me too. It would. I think it would make a significant difference, but I just can't get myself to that place where I'm motivated."

Lack of resources to support healthy choices

> "I'm traveling a lot and...when l'm traveling, it's just really hard to...find a gym, and...find a healthy place to eat."

- "I just live in a smaller community and nothing like that (a DPP) is really around... where I live, so there's not really a whole lot of access to some of that stuff."

getting type 2 diabetes was cited by 13 engagers, one of whom noted, "If it hadn't been for the prediabetes I probably would have left it where I was at. So that definitely was a big motivator." In addition, engagers described barriers they faced while engaging in behaviors to prevent type 2 diabetes: 17 cited competing demands, 11 mentioned periods of low motivation, and 11 identified people in their social network who impeded their efforts.

Among the 18 non-engagers, the predominant barrier to engagement in behaviors to prevent type 2 diabetes, cited by 16 participants, was competing demands such as work or family responsibilities. One participant explained, "The kids get busy in school and activities and...stuff for myself seems to be the first thing that gets cut out." The next most common barrier, cited by 12 participants, was insufficient motivation to engage in behavior change. One participant who faced this challenge said, "The answer is I need to put myself on a program and stick to it. If I do that, it'll work. I just need to be motivated and take the time and effort...the only problem is me." Ten participants described lack of resources, such as affordable healthy foods or exercise facilities to support healthy choices, as a key barrier. For example, one participant stated, "I don't understand why it just seems so much harder to buy the healthier foods, the salads...I incorporate it in my diet every day but, you know after a while you have to stretch your money and... sometimes all you can get is lunch meat and bread." Non-engagers also described facilitators of attempts to engage in behaviors to prevent type 2 diabetes: eight cited external resources or tools (eg, rewards and activity 
trackers), seven identified supportive people in their social network, and seven mentioned access to key resources like exercise facilities or healthy foods.

\section{DISCUSSION}

In this study of employees found in a workplace screening to have pre-diabetes, most had engaged in at least one recommended behavior to prevent type 2 diabetes in the 3-month period after the screening. Using both quantitative and qualitative data we also identified key facilitators of and barriers to this engagement. While others studies have examined the relationship between awareness of a pre-diabetes diagnosis and risk-reducing behaviors, ${ }^{1} 2033$ our study is one of the first to describe the frequency of engagement in risk-reducing behaviors to prevent type 2 diabetes among employees found to have pre-diabetes through a workplace screening and to identify key opportunities to optimize their engagement in preventive strategies.

Many more employees we surveyed $\sim 3$ months after they were screened reported engaging in self-directed efforts to lose weight and achieve recommended levels of physical activity than in a community DPP. While the main DPP clinical trial identified specific weight loss and physical activity targets that individuals can aim for to prevent or delay the onset of type 2 diabetes, ${ }^{7}$ it is unclear whether such individually-directed efforts can be as effective in preventing or delaying the onset of type 2 diabetes as formal programs such as DPPs that offer structured, ongoing support. ${ }^{11}{ }^{34}$ Although the DPP continues to be disseminated in communities across the USA, ${ }^{9}$ including southeast Michigan where many of the study participants lived, our interviews revealed that competing demands such as work and family responsibilities often impeded engagement in structured programs inside or outside of the workplace. An alternative approach that could help some busy employees engage in behavior change while still receiving ongoing support would be to encourage them to engage in online versions of the DPP that can be accessed on demand. ${ }^{35}$

Nearly one in five employees we surveyed had discussed metformin with a primary care provider since the biometric screening. Although we did not ask participants whether they were actually taking metformin for the prevention of type 2 diabetes at follow-up, our results suggest that prompting discussion of metformin with a primary care provider could be a way to spur people with pre-diabetes to be considered for this preventive therapy.

As more Americans with pre-diabetes are likely to be diagnosed through the AMA-CDC Prevent Diabetes STAT initiative ${ }^{14}$ and the US Preventive Services Task Force's recent broadening of criteria for screening for type 2 diabetes ${ }^{15}$ our findings point to several potential opportunities to optimize engagement of these individuals in efforts to reduce their risk for type 2 diabetes. For example, in our surveys we found that engagers had more modest perceptions of their risk for type 2 diabetes than non-engagers. It is possible that more modest risk perceptions-in which there is perhaps a recognition that risk for type 2 diabetes is elevated yet the development of type 2 diabetes is not felt to be a foregone conclusion-could yield less anxiety and thus leave individuals better poised to take preventive actions. ${ }^{18} 262736$ Alternatively, perceived risk could have been lower among individuals who were engaged in behaviors to prevent type 2 diabetes because they were taking action to reduce their risk. Either way, this finding suggests that different levels and types of perceptions of risk for type 2 diabetes may be closely related to behaviors to prevent type 2 diabetes and should be closely examined in future research.

We also found that engagers had higher levels of motivation-including both greater autonomous and controlled motivation-to prevent type 2 diabetes. Further, the importance of motivation was voiced repeatedly among interviewed respondents. This finding reinforces the critical importance of enhancing motivation to prevent type 2 diabetes as another key ingredient for engagement in evidence-based preventive strategies. Future research should focus on testing promising strategies to bolster levels of motivation to prevent type 2 diabetes such as motivational interviewing, ${ }^{37}$ tailored messaging, ${ }^{38}$ peer support, ${ }^{39}$ financial incentives, and different combinations of these approaches. ${ }^{40}$ Since autonomous motivation is more likely to produce longterm, sustained behavior change than controlled motivation, ${ }^{30}$ it will be important to track the degree to which such intervention strategies affect different types of motivation to prevent type 2 diabetes and whether those with higher levels of autonomous motivation indeed sustain healthy behaviors to a greater degree than those with controlled motivation.

Another important difference between engagers and non-engagers was their level of patient activation, which refers to individuals' overall understanding of their roles in healthcare processes, as well as having the knowledge, skills, and confidence to manage their own health. ${ }^{41}$ In this case, individuals who were more activated prior to the screening may have been better able to translate information about pre-diabetes into engagement in preventive strategies. Alternatively, information about prediabetes may have preferentially boosted activation in some individuals, thus leading them to engage in preventive strategies. Though we are unable to determine which of these dynamics occurred in our study, both potential explanations suggest patient activation may play an important role in facilitating engagement in recommended behaviors to prevent type 2 diabetes and thus should be examined in future research.

Key facilitators of engagement that emerged in our interviews included assistance and encouragement from social networks ${ }^{42}$ as well as use of external supports such as tracking devices. Important barriers to engagement included competing demands and insufficient resources 
for healthy behaviors. These factors could be leveraged either alone or in combination in the design of approaches to promote engagement in behaviors to prevent type 2 diabetes. Some examples of approaches suggested by our findings include sharing information about pre-diabetes with key members of an individual's social network, ${ }^{43}$ providing ready access to devices to track weight, food intake and physical activity, ${ }^{44}$ building competence and self-efficacy to integrate preventive behaviors into busy schedules, ${ }^{45}$ and/or enhancing access to affordable, nutritious foods and exercise opportunities. ${ }^{46}$

Additionally, both engagers and non-engagers identified social support and external tools as key facilitators of engagement, and competing demands and low motivation as important barriers to engagement. More research is needed to understand the factors that enable engagers to successfully capitalize on these shared facilitators and overcome these shared barriers so that these factors can be taken into account in the design of interventions to promote engagement in behaviors to prevent type 2 diabetes.

\section{Limitations}

Our data rely on participant self-report and focus only on engagement in preventive strategies $\sim 3$ months after a workplace screening. Our sample may not be representative of other populations, particularly those with lower incomes or less education. Although the StayWell health coaches invited study participation from all employees found to have pre-diabetes, and key demographic characteristics of study participants and all employees found to have pre-diabetes in the screening were similar, employees who were already engaged in behaviors to prevent type 2 diabetes could have been more likely to participate in the study. Further, because of our study design we were unable to determine whether postscreening engagement in recommended behaviors was a direct result of the screening. We did not inquire about participants' BMI and were unable to measure how successful individuals who were trying to lose weight had been (ie, how much progress they had made towards losing $7 \%$ of their body weight as recommended). We measured physical activity through a widely used survey scale, which may be less valid and reliable than objective measures of physical activity. Finally, we were unable to link our survey and interview data to other biometric screening and HRA data that had been collected during the workplace screening.

In conclusion, most employees with pre-diabetes who we surveyed had engaged in at least one recommended strategy to prevent type 2 diabetes $\sim 3$ months after they had been found to have pre-diabetes during a workplace screening. Further, we identified key facilitators of and barriers to engagement in recommended preventive behaviors. More research is needed to understand employees' reactions to and understanding of a prediabetes diagnosis, measure longer-term engagement in preventive behaviors among employees with pre- diabetes, and test promising strategies to optimize their ongoing engagement in strategies to delay or prevent the onset of type 2 diabetes.

Author affiliations

${ }^{1}$ VA Center for Clinical Management Research, VA Ann Arbor Healthcare System, Ann Arbor, Michigan, USA

${ }^{2}$ Department of Internal Medicine, University of Michigan Medical School, Ann Arbor, Michigan, USA

${ }^{3}$ University of Michigan Institute for Healthcare Policy and Innovation, Ann Arbor, Michigan, USA

${ }^{4}$ MHealthy Administration, University of Michigan Health and Well-being Services, Ann Arbor, Michigan, USA

${ }^{5}$ Department of Health Behavior and Health Education, University of Michigan School of Public Health, Ann Arbor, Michigan, USA

Acknowledgements The authors thank Jackie Miller of the Department of Internal Medicine in the University of Michigan Medical School for her assistance with conducting telephone interviews and coding the interview transcripts. The views expressed in this article are those of the authors and do not necessarily reflect the position or policy of the Department of Veterans Affairs or the US government.

Contributors JTK researched data, wrote the manuscript, and takes full responsibility for the work as a whole, including the study design, access to data, and the decision to submit and publish the manuscript. MK researched data and reviewed/edited the manuscript. KRJ. reviewed/edited the manuscript. $\mathrm{MH}$ reviewed/edited the manuscript and contributed to discussion.

Funding This research was supported by a Pilot and Feasibility Grant from the Michigan Center for Diabetes Translational Research-MCDTR (NIH Grant P30-DK092926). Support was also provided by the Department of Veterans Affairs, Veterans Health Administration, Health Services Research and Development Service. JTK is a VA HSR\&D Career Development awardee at the Ann Arbor VA.

Competing interests JK has received consulting fees from HealthMine and SeeChange Health.

Ethics approval University of Michigan Medical School Institutional Review Board.

Provenance and peer review Not commissioned; externally peer reviewed.

Data sharing statement Unpublished data from the study are available by contacting the corresponding author.

Open Access This is an Open Access article distributed in accordance with the Creative Commons Attribution Non Commercial (CC BY-NC 4.0) license, which permits others to distribute, remix, adapt, build upon this work noncommercially, and license their derivative works on different terms, provided the original work is properly cited and the use is non-commercial. See: http:// creativecommons.org/licenses/by-nc/4.0/

\section{REFERENCES}

1. Geiss LS, James C, Gregg EW, et al. Diabetes risk reduction behaviors among U.S. adults with prediabetes. Am J Prev Med 2010;38:403-9.

2. Zhang X, Gregg EW, Williamson DF, et al. A1C level and future risk of diabetes: a systematic review. Diabetes Care 2010;33:1665-73.

3. Levitan EB, Song Y, Ford ES, et al. Is nondiabetic hyperglycemia a risk factor for cardiovascular disease? A meta-analysis of prospective studies. Arch Intern Med 2004;164:2147-55.

4. DeFronzo RA, Abdul-Ghani M. Assessment and treatment of cardiovascular risk in prediabetes: impaired glucose tolerance and impaired fasting glucose. Am J Cardiol 2011;108(3 Suppl):3B-24B.

5. Grundy SM. Pre-diabetes, metabolic syndrome, and cardiovascular risk. J Am Coll Cardiol 2012;59:635-43.

6. Selvin E, Steffes MW, Zhu H, et al. Glycated hemoglobin, diabetes, and cardiovascular risk in nondiabetic adults. $N$ Engl $\mathrm{J} \mathrm{Med}$ 2010;362:800-11.

7. Tuomilehto J, Lindström J, Eriksson JG, et al. Prevention of type 2 diabetes mellitus by changes in lifestyle among subjects with impaired glucose tolerance. N Engl J Med 2001;344:1343-50. 
8. Diabetes Prevention Program Research Group. 10-year follow-up of diabetes incidence and weight loss in the Diabetes Prevention Program Outcomes Study. Lancet 2009;374:1677-86.

9. Albright AL, Gregg EW. Preventing type 2 diabetes in communities across the U.S.: the National Diabetes Prevention Program. Am J Prev Med 2013;44(Suppl 4):S346-51.

10. America's Health Insurance Plans-Health Plans Preventing Diabetes and Improving Well-Being. (cited 25 November 2015). http://www.ahip.org/prediabetes/

11. American Diabetes Association. Standards of medical care in diabetes--2014. Diabetes Care 2014;37(Suppl 1):S14-80.

12. Claxton G, Rae M, Panchal N, et al. Health benefits in 2014: stability in premiums and coverage for employer-sponsored plans. Health Aff (Millwood) 2014;33:1851-60.

13. 19th Annual Towers Watson/National Business Group on Health Employer Survey on Purchasing Value in Health Care. Towers Watson. (cited 10 November 2014). http://www.towerswatson.com/ en-US/Insights/IC-Types/Survey-Research-Results/2014/05/fullreport-towers-watson-nbgh-2013-2014-employer-survey-onpurchasing-value-in-health-care

14. Prevent Diabetes STATIGeneral Public. Prevent Diabetes STAT. (cited 28 November 2015). http://www.preventdiabetesstat.org

15. Selph S, Dana T, Blazina I, et al. Screening for type 2 diabetes mellitus: a systematic review for the U.S. preventive services task force screening for type 2 diabetes mellitus. Ann Intern Med 2015;162:765-76.

16. Eborall H, Davies R, Kinmonth AL, et al. Patients' experiences of screening for type 2 diabetes: prospective qualitative study embedded in the ADDITION (Cambridge) randomised controlled trial. BMJ 2007;335:490.

17. Eborall H, Stone M, Aujla N, et al. Influences on the uptake of diabetes screening: a qualitative study in primary care. $\mathrm{Br} J$ Gen Pract 2012;62:e204-11.

18. Troughton J, Jarvis J, Skinner C, et al. Waiting for diabetes: perceptions of people with pre-diabetes: a qualitative study. Patient Educ Couns 2008;72:88-93.

19. Mezuk B, Johnson-Lawrence $\mathrm{V}$, Lee $\mathrm{H}$, et al. Is ignorance bliss? Depression, antidepressants, and the diagnosis of prediabetes and type 2 diabetes. Health Psychol 2013;32:254-63.

20. Gopalan A, Lorincz IS, Wirtalla C, et al. Awareness of prediabetes and engagement in diabetes risk-reducing behaviors. Am J Prev Med 2015;49:512-19.

21. Standards of medical care in diabetes-2015: summary of revisions. Diabetes Care 2015;38 (Suppl):S4.

22. Chew LD, Griffin JM, Partin MR, et al. Validation of screening questions for limited health literacy in a large VA outpatient population. J Gen Intern Med 2008;23:561-6.

23. Chew LD, Bradley KA, Boyko EJ. Brief questions to identify patients with inadequate health literacy. Fam Med 2004;6:588-94.

24. Prochaska JO, Redding CA, Evers KE. The transtheoretical model and stages of change. In: Glanz K, Rimer BK, Viswanath K, eds. Health behavior and health education: theory, research, and practice. 4th edn. San Francisco, CA: John Wiley \& Sons, Inc, 2008:97-121

25. Craig CL, Marshall AL, Sjöström M, et al. International physical activity questionnaire: 12-country reliability and validity. $\mathrm{Med} \mathrm{Sci}$ Sports Exerc 2003;35:1381-95.

26. Adriaanse MC, Snoek FJ, Dekker JM, et al. Perceived risk for type 2 diabetes in participants in a stepwise population-screening programme. Diabet Med 2003;20:210-15.
27. Adriaanse MC, Twisk JWR, Dekker JM, et al. Perceptions of risk in adults with a low or high risk profile of developing type 2 diabetes; a cross-sectional population-based study. Patient Educ Couns 2008;73:307-12.

28. Levesque CS, Williams GC, Elliot D, et al. Validating the theoretical structure of the Treatment Self-Regulation Questionnaire (TSRQ) across three different health behaviors. Health Educ Res 2007;22:691-702.

29. Williams GC, Niemiec CP, Patrick $\mathrm{H}$, et al. The importance of supporting autonomy and perceived competence in facilitating long-term tobacco abstinence. Ann Behav Med 2009;37:315-24.

30. Deci EL, Ryan RM. The "What" and "Why" of Goal Pursuits: human needs and the self-determination of behavior. Psychol Inq 2000;11:227-68.

31. Crabtree BF, Miller WL. Doing qualitative research. SAGE, 1999. $432 \mathrm{p}$.

32. Sandelowski M, Barroso J. Writing the proposal for a qualitative research methodology project. Qual Health Res 2003;13:781-820.

33. Okosun IS, Lyn R. Prediabetes awareness, healthcare provider's advice, and lifestyle changes in American adults. Int $J$ Diabetes Mellit 2010. (cited 29 August 2012). http://www.sciencedirect.com/ science/article/pii/S1877593410001074.

34. Schellenberg ES, Dryden DM, Vandermeer B, et al. Lifestyle interventions for patients with and at risk for type 2 diabetes: a systematic review and meta-analysis. Ann Intern Med 2013;159:543-51.

35. Sepah SC, Jiang L, Peters AL. Translating the diabetes prevention program into an online social network: validation against CDC standards. Diabetes Educ 2014;40:435-43.

36. Hivert M-F, Warner AS, Shrader P, et al. Diabetes risk perception and intention to adopt healthy lifestyles among primary care patients. Diabetes Care 2009;32:1820-2.

37. Britt E, Hudson SM, Blampied NM. Motivational interviewing in health settings: a review. Patient Educ Couns 2004;53:147-55.

38. Krebs P, Prochaska JO, Rossi JS. A meta-analysis of computer-tailored interventions for health behavior change. Prev Med 2010;51:214-21.

39. Brownson CA, Heisler M. The role of peer support in diabetes care and self-management. Patient 2009;2:5-17.

40. Ries NM. Financial incentives for weight loss and healthy behaviours. Healthc Policy 2012;7:23-8.

41. Hibbard $\mathrm{JH}$, Greene J. What the evidence shows about patient activation: better health outcomes and care experiences; fewer data on costs. Health Aff (Millwood) 2013;32:207-14.

42. Chang MH, Valdez R, Ned RM, et al. Influence of familial risk on diabetes risk-reducing behaviors among U.S. adults without diabetes. Diabetes Care 2011;34:2393-9.

43. Baig AA, Benitez A, Quinn MT, et al. Family interventions to improve diabetes outcomes for adults. Ann N Y Acad Sci 2015;1353:89-112.

44. Piette JD, List J, Rana GK, et al. Mobile health devices as tools for worldwide cardiovascular risk reduction and disease management. Circulation 2015:132:2012-27.

45. Miller CK, Weinhold KR, Marrero DG, et al. A translational worksite diabetes prevention trial improves psychosocial status, dietary intake, and step counts among employees with prediabetes: a randomized controlled trial. Prev Med Rep 2015;2:118.

46. Pridgeon $A$, Whitehead K. A qualitative study to investigate the drivers and barriers to healthy eating in two public sector workplaces. J Hum Nutr Diet 2013;26:85-95. 